Review Article

OOpen Access

CrossMark

\title{
CD44: a multifaceted molecule in cancer progression
}

\begin{abstract}
CD44, a single pass transmembrane glycoprotein, initially characterized as lymphocyte homing receptor, has now been implicated in various stages of cancer development. The Anomaly in CD44 expression distinguishes most human cancers. CD44 is also identified as cancer stem cell marker. This review will comprehend the versatile role of CD44 during cancer initiation, proliferation, invasion, metastasis and as the regulator of cancer cell metabolism.
\end{abstract}

Keywords: CD44; Cancer; Alternate splicing; Migration; Angiogenesis
Volume 8 Issue $3-2017$

\section{Vivek Anand, Alpana Sharma \\ Department of Biochemistry, All India Institute of Medical Sciences (AlIMS), India}

Correspondence: Alpana Sharma, Department of Biochemistry, All India Institute of Medical Sciences (AlIMS), New Delhi - I 10029, India. Tel: +9|- I I-26546665; Email dralpanasharma@gmail.com

Received: May 25, 2017 | Published: August 17, 2017
Abbreviations: CD44v, CD44 variant; $\mathrm{CD} 44 \mathrm{~s}, \mathrm{CD} 44$ standard; ECM, extracellular matrix; MMP, matrix metalloproteinase; TNF- $\alpha$, tumor necrosis factor alpha; JNK, jun n-terminal kinase

\section{Introduction}

CD44, also known as lymphocyte homing receptor, HUTCH-1, Hermes, H-CAM, and Ly-24, is a glycoprotein involved in cell to extra cellular matrix (ECM) interaction, cell to cell interaction, in cell signaling and migration of tumor cells. In humans, it is encoded by the gene located on chromosome $11 \mathrm{p} 13 .{ }^{1}$. CD44 gene consists of 20 exons, of which 10 flanking exons (5 each side) are known as standard (or constant) exons and 10 central exons as variable exons which undergo extensive splicing (Figure 1). Isoforms containing CD44v exons are found to be expressed in various cancers. ${ }^{2}$ Protein expressed by $C D 44$ gene has the molecular weight of around $85-200 \mathrm{kDa}$ and contains three functional domains: extracellular, transmembrane and intracellular domain. The amino-terminal domain coded by the first five exons of $C D 44 s$ isoform is connected with the plasma membrane by a short stem structure, containing proteolytic cleavage sites. ${ }^{3}$ This extracellular domain is found to be the most diverse region. Sequences encoded by alternative splicing of exons v1-v10 are inserted at stem region which acts as ligand binding site. ${ }^{1}$ CD44 is the best characterized Hyaluronic acid (HA) receptor and is the principal mediator of HA signaling. Differing HA levels are found in different cancers and they also correlate with CD44 expression. ${ }^{4,5}$ Osteopontin, laminin, collagen, integrin, MMPs (matrix metalloproteinase), and other components of ECM also act as CD44 ligands. ${ }^{6}$

\section{Role of CD44 in cancer proliferation}

Expression of CD44 is associated with an augmented potential for tumor initiation and progression as shown in the gastric cancer mouse model where CD44+/+ animals developed large gastric tumors in around 30-50 weeks of age, whereas, CD44-/- mouse developed smaller tumors. In $\mathrm{CD} 44+/+$ mouse gene expression analysis revealed elevated expression of CD44v8-10 variant isoforms. ${ }^{7} \mathrm{~A}$ similar finding was also observed in glioma mouse model suggesting the importance of CD44 in cancer stemness. ${ }^{8}$ Some recent studies have exhibited CD44 as cancer stem cell marker in breast, gastric, pancreatic, colorectal and other cancers. ${ }^{9-17}$ Different tumor types and their associated cells in the microenvironment express probably different sets of CD44 isoforms with a varied combination of variants. TNF- $\alpha$ has been found to upregulate CD44v3 and CD44v6 expression through the $\mathrm{JNK}$ or p38 pathway resulting in increased migration capacity of breast cancer cells in vitro. ${ }^{18} \mathrm{CD} 44 \mathrm{v} 6$ is suggested to be involved in breast and colorectal cancers and also contributes in the aggressiveness of non-Hodgkin's lymphomas. ${ }^{19} \mathrm{CD} 44 \mathrm{v} 6$ has been observed to function as the coreceptor for EGF (Epidermal growth factor) and HGF (Hepatocyte growth factor), in addition CD44v3 also functions as the coreceptor for VEGF (Vascular endothelial growth factor) and FGF (Fibroblast growth factor) to form a complex with associated receptors enhancing receptor tyrosine kinase activity and in turn mediating CD44 signaling critical for stemness property of cancer cells. ${ }^{6,20}$ Overall, literature confirms that there is a cancerspecific expression of CD44 variants.

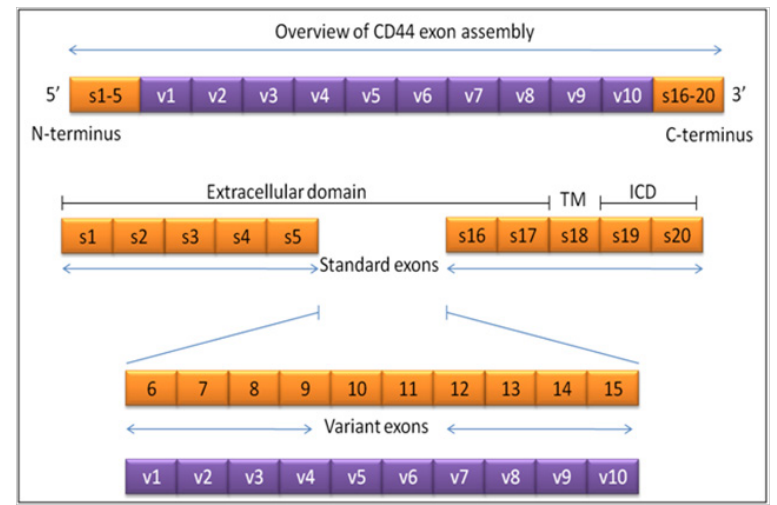

Figure I Schematic diagram of CD44 gene assembly. There are 10 standard exons (sI-5 and sI6-20) that codes for CD44s protein. There are 10 variable exons (6-I5 or $\mathrm{vl}-\mathrm{vIO})$ that codes for the CD44v protein and undergo alternate splicing.

TM, transmembrane; ICD, intracellular domain

\section{CD44 promotes migration, invasion, and angiogenesis of tumor}

There are numerous studies that focus on the mechanism by which CD44 mediate migration, proliferation, and invasion of tumor cells. By dynamic regulation of actin cytoskeleton that attaches with the cytoplasmic domain of CD44 receptor, formation of cell's 
adhesive structure is regulated. Specialized structural dynamics for migration of a cell is regulated by a temporal organization of actin-binding proteins. ${ }^{21,22}$ Interaction of CD44 receptor with matrix metalloproteinase 9 (MMP9) causes secretion of MMP9, promoting migration and invasion of PC3 (Prostate cancer) cells. ${ }^{23}$ Furthermore, CD44v3 upregulates cytoskeleton functions through ankyrin by activating the actomyosin contractile complex that facilitates migration in head and neck squamous carcinoma cell line. ${ }^{24}$ Angiogenic potential of CD44 has been established by using CD44null mice to study angiogenic responses where wound healing and vascularization both were found to be impaired in matrigel implants. This suggests that tumor cells facilitate its extravasation by vascular adhesion and augmented CD44 expression by angiogenic factors (eg. VEGF). ${ }^{25}$

\section{CD44 Acts as a transcription factor in cancer}

There is another functional importance of CD44 as a transcription factor. The $12 \mathrm{kDa}$ intracellular domain generated by sequential cleavage of CD44 by membrane type 1 matrix metalloproteinase (MT1-MMP) and presenilin- $1 / \gamma$-secretase enzyme translocates to the nucleus to activate transcription of numerous proteins including CD44. Expression of these proteins ultimately helps cancer cell adhesion, proliferation, migration, and invasion..$^{26,27}$

\section{Regulation of cancer cell metabolism by CD44}

Most of the cancer cells specifically those having aggressive properties develop a mechanism to protect themselves from ROS (Reactive oxygen species). Cancer cell depends on glycolysis for ATP production regardless of oxygen availability. This unique metabolism by aerobic glycolysis is called 'Warburg effect'. This mechanism is accompanied by suppression of mitochondrial respiration in cancer cells, reducing production of ROS, and ultimately conferring resistance to chemotherapy. ${ }^{28}$ Pyruvate kinase isozyme type 2 (PKM2), which is mainly expressed in tumors plays an essential role in this process. It has been observed that low activity of the PKM2 enzyme in cancer cells promote the conversion of pyruvate to lactate and the flow of glycolytic intermediates into biosynthetic pathway through the generation of NADPH. ${ }^{29}$ CD44 interacts with PKM2 and suppresses its activity, thus promoting glycolysis and antioxidant status in cancer cells. ${ }^{30}$

Another important enzyme 6-phosphofructo-2-kinase/fructose2,6-bisphosphatase 4 (PFKFB4), an isoform of phosphofructokinase 2 (PFK2), has been found to be differentially expressed in the benign and malignant form of prostate cancer. In small cell neuroendocrine carcinoma (SCNC) of the prostate, it is found to be highly expressed as compared to adenocarcinoma cells of the prostate. CD44 is found to regulate expression of the PFKFB4 enzyme in prostatic PC-3 cells (SCNC) as knockdown of CD44 reduced expression of protein and mRNA of PFKFB4 and also increased ROS levels. ${ }^{31,32}$ Knockdown of CD44 also increased the sensitivity of SCNC tumor cells to carboplatin. ${ }^{32}$ These reports confirm the multifaceted role of CD44 in the progression of cancer.

\section{The clinical implication of CD44 in tumors}

There are myriad of literature that suggests overexpression of CD44, predominantly isoforms with CD44v exons in various cancers. These findings supported the efforts that take heed on the diagnostics and/or prognostic importance of CD44 isoforms in cancer and its implication as a diagnostic/prognostic marker. CD44s and CD44v have been reported as the prognostic marker for prostate cancer. The importance of CD44 and CD44v6 expression is linked with survival and staging of pancreatic cancer. ${ }^{33}$ In hepatocellular carcinoma $\mathrm{CD} 44, \mathrm{CD} 44 \mathrm{~s}$ and CD44v6 have clinical significance in prognosis, recurrence, and survival. Likewise, in gastric cancer CD44, CD44v6 and $\mathrm{CD} 44 \mathrm{v} 9$ have been found to be associated with metastasis, recurrence, survival, staging, and prognosis. There are many other cancers such as renal cell carcinoma, osteosarcoma, lung cancer, neuroblastoma, colorectal cancer, breast cancer, head and neck cancer, bladder cancer and leukemia where CD44 has been demonstrated as a prognostic marker (Table 1). ${ }^{34,35}$

Table I Multifaceted function of CD44 variants ${ }^{33,34}$

\begin{tabular}{|c|c|c|}
\hline CD44 variants & function & Prognostic marker in cancer type \\
\hline CD44vl & $\begin{array}{l}\text { It may generate a soluble truncated protein due to } \\
\text { the premature termination codon. }\end{array}$ & --- \\
\hline CD44v2 & $\begin{array}{l}\text { Specific function of CD44v2 in stem cell has not been } \\
\text { established. }\end{array}$ & ${ }^{\mathrm{n}}$ Colorectal cancer \\
\hline CD44v2-10 & $\begin{array}{l}\text { Endows metastatic phenotype to a non-metastatic } \\
\text { SKHepl cells. }\end{array}$ & Hepatocellular carcinoma \\
\hline CD44v3 & $\begin{array}{l}\text { Forms CD } 44 v 3 / O c t 4 / S o x 2 / \text { Nanog complex. It } \\
\text { translocates to the nucleus and activates miR-302, } \\
\text { which in turn suppresses epigenetic regulators. }\end{array}$ & $\begin{array}{l}\text { Leukemia, Endometrial cancer,Vulvar cancer, Oral squamous cell } \\
\text { carcinoma (OSCC), Urothelial cancer, Bladder cancer }\end{array}$ \\
\hline CD44v3, v8-10 & $\begin{array}{l}\text { Detected in }>90 \% \text { of adenomas and colorectal } \\
\text { carcinomas. }\end{array}$ & Colorectal cancer, Urothelial cancer, Bladder cancer \\
\hline CD44v4 & $\begin{array}{l}\text { Mediates breast cancer adhesion to endothelial cells } \\
\text { via E-selectin. }\end{array}$ & Breast cancer, Leukemia \\
\hline CD44v5 & $\begin{array}{l}\text { Activated Ras produce CD } 44 \text { isoforms containing } \\
\text { CD } 44 v 5 \text { by the interaction of v5 with RNA splicing } \\
\text { regulator proteins SRm I } 60 \text { and Sam } 64 \text {. }\end{array}$ & $\begin{array}{l}\text { Papillary thyroid carcinoma, Renal cell carcinoma, Osteosarcoma, } \\
\text { Neuroblastoma, Leukemia }\end{array}$ \\
\hline CD44v6 & $\begin{array}{l}\text { Supports assembly of the soluble matrix during pre- } \\
\text { metastatic niche formation. This assembled matrix } \\
\text { promotes cell motility through phosphorylation of } \\
\text { c-Met, Ezrin, and FAK. Confers resistance to cisplatin. } \\
\text { Promotes endothelial cell migration. }\end{array}$ & $\begin{array}{l}\text { Papillary thyroid carcinoma, Renal cell carcinoma, Prostate cancer, } \\
\text { Pancreatic cancer, Osteosarcoma, Lung cancer, Hepatocellular } \\
\text { carcinoma, Laryngeal, oral and head \& neck cancer, Gastric } \\
\text { cancer, Leukemia, Urothelial cancer, Bladder cancer,Vulvar cancer, } \\
\text { Endometrial cancer }\end{array}$ \\
\hline
\end{tabular}


Table continued...

\begin{tabular}{|c|c|c|}
\hline CD44 variants & function & Prognostic marker in cancer type \\
\hline CD44v7 & $\begin{array}{l}\text { CD44v7-positive stromal cells support hematopoietic } \\
\text { progenitor cell homing. }\end{array}$ & c-- \\
\hline CD44v8-10 & $\begin{array}{l}\text { Stabilizes the glutamate-cystine transporter at plasma } \\
\text { membrane promoting uptake of cystine for GSH } \\
\text { synthesis. Cells become resistant to antioxidant } \\
\text { treatment. }\end{array}$ & Biliary tract cancer, Urothelial cancer, Bladder cancer \\
\hline CD44v9 & $\begin{array}{l}\text { Hyaluronic acid (HA)/ CD44v9 interaction promotes } \\
\text { Androgen receptor (AR) gene expression, cell } \\
\text { adhesion, and proliferation. }\end{array}$ & Gastric cancer, Leukemia, Colorectal cancer \\
\hline CD44v10 & $\begin{array}{l}\text { Promotes adhesion and maturation of bone marrow } \\
\text { stromal cells into primary B-cells. CD } 44 \mathrm{v} / 0 \text { blocking } \\
\text { antibodies induce mobilization of progenitor cells and } \\
\text { delay in maturation. }\end{array}$ & Renal cell carcinoma \\
\hline
\end{tabular}

\section{Conclusion}

There is a substantial genetic reorganization of the CD44 glycoprotein by the mechanism of alternative splicing events that produces CD44 variant isoforms which are expressed distinctively in different cancers, as compared to the standard CD44 isoforms. CD44 promotes tumor migration, invasion, and angiogenesis by dynamic regulation of various intracellular and extracellular proteins. The versatile role of CD44 includes its function as the transcription factor and as the regulator of cancer cell metabolism. Furthermore, the clinical relevance of this multifaceted molecule increases by its use as diagnostic and/or prognostic marker. A study involving identification of the regulatory mechanism for cancer specific expression of CD44 isoforms is very much warranted to restrain the development of cancer stem cells. Moreover, targeting CD44 and its specific variants by molecular methods (e.g. siRNA, anti-CD44 antibody) may unravel a unique paradigm in cancer management.

\section{Conflicts of interest}

The authors declare that there is no conflict of interests regarding the publication of this paper.

\section{Acknowledgements}

None.

\section{Funding}

None.

\section{References}

1. Goldstein LA, Zhou DF, Picker LJ, et al. A human lymphocyte homing receptor, the hermesantigen is related to cartilage proteoglycan core and link proteins Cell. 1998;56(6):1063-1072.

2. Matsumura Y, Tarin D. Significance of CD44 gene products for cancer diagnosis and disease evaluation. Lancet. 1992;340(8827):1053-1058.

3. Okamoto I, Kawano Y, Murakami D, et al. Proteolytic release of CD44 intracellular domain and its role in the CD44 signaling pathway. The Journal of Cell Biology. 2001;155(5):755-762.

4. Kosunen A, Ropponen K, Kellokoski J, et al. Reduced expression of hyaluronan is a strong indicator of poor survival in oral squamous cell carcinoma. Oral Oncology. 2004;40(3):257-263.

5. Karjalainen JM, Tammi RH, Tammi MI, et al. Reduced level of CD44 and hyaluronan associated with unfavorable prognosis in clinical stage I cutaneous melanoma. Am J Pathol. 2000;157(3):957-965.
6. Ponta H, Sherman L, Herrlich PA. CD44: from adhesion molecules to signalling regulators. Nature reviews Molecular Cell Biology. 2003;4(1):33-45.

7. Ishimoto $\mathrm{T}$, Nagano $\mathrm{O}$, Yae $\mathrm{T}$, et al. CD44 variant regulates redox status in cancer cells by stabilizing the XCT subunit of system $\mathrm{xc}(-)$ and thereby promotes tumor growth. Cancer Cell. 2011;19(3):387-400.

8. Pietras A, Katz AM, Ekström EJ, et al. Osteopontin-CD44 signaling in the glioma perivascular niche enhances cancer stem cell phenotypes and promotes aggressive tumor growth. Cell Stem Cell. 2014;14(3):357-369.

9. Bánky B, Rásó-Barnett L, Barbai T, et al. Characteristics of CD44 alternative splice pattern in the course of human colorectal adenocarcinoma progression. Molecular cancer. 2012;11(1):83.

10. Zhu J, He J, Liu Y, Simeone DM, et al. Identification of glycoprotein markers for pancreatic cancer $\mathrm{CD} 24+\mathrm{CD} 44+$ stem-like cells using nanoLC-MS/MS and tissue microarray. J Proteome Res. 2012;11(4):22722281.

11. Dalerba P, Dylla SJ, Park IK, et al. Phenotypic characterization of human colorectal cancer stem cells. Proc Natl Acad Sci U S A. 2007;104(24):10158-10163.

12. Alderton G. Tumour stem cells: generating colon cancer. Nat Rev Cancer. 2006;6:906-907.

13. Fillmore C, Kuperwasser C. Human breast cancer stem cell markers CD44 and CD24: enriching for cells with functional properties in mice or in man? Breast Cancer Res. 2007;9(3):303.

14. Takaishi S, Okumura T, Tu S, et al. Identification of Gastric Cancer Stem Cells Using the Cell Surface Marker CD44. Stem Cells. 2009;27(5):1006-1020.

15. Li C, Heidt DG, Dalerba P, et al. Identification of pancreatic cancer stem cells. Cancer Res. 2007;67(3):1030-1037.

16. Koukourakis MI, Giatromanolaki A, Tsakmaki V, et al. Cancer stem cell phenotype relates to radio-chemotherapy outcome in locally advanced squamous cell head-neck cancer. Br J Cancer. 2012;106(5):846-853.

17. Hu Y, Fu L. Targeting cancer stem cells:a new therapy to cure cancer patients. Am J Cancer Res. 2012;2(3):340-356.

18. Li J1, Zha XM, Wang R, et al. Regulation of CD44 expression by tumor necrosis factor- $\alpha$ and its potential role in breast cancer cell migration. Biomed Pharmacother. 2012;66(2):144-150.

19. Akisik E, Bavbek S, Dalay N. CD44 variant exons in leukemia and lymphoma. Pathol Oncol Res. 2002;8(1):36-40.

20. Zhao P1, Damerow MS, Stern P, et al. CD44 promotes Kras-dependent lung adenocarcinoma. Oncogene. 2013;32(43):5186-5190. 
21. Linder S, Aepfelbacher M. Podosomes: adhesion hot-spots of invasive cells. Trends Cell Biol. 2003;13(7):376-385.

22. Desai B, Ma T, and Chellaiah MA. Invadopodia and matrix degradation, a new property of prostate cancer cells during migration and invasion. $J$ Biol Chem. 2008;283(20):13856-13866.

23. Desai B, Rogers M J, Chellaia M A. Mechanisms of osteopontin and CD44 as metastatic principles in prostate cancer cells. Mol Cancer. 2007;6:18.

24. Franzmann EJ, Weed DT, Civantos FJ, et al. A novel CD44 v3 isoform is involved in head and neck squamous cell carcinoma progression. Otolaryngol. Head Neck Surg. 2001;124(4):426-432.

25. Cao G, Savani RC, Fehrenbach M, et al. Involvement of endothelial CD44 during in vivo angiogenesis. Am. Pathol. 2006;169(1):325-336.

26. Okamoto I, Kawano Y, Murakami D, et al. Proteolytic release of CD44 intracellular domain and its role in the CD44 signaling pathway. $J$ Cell Biol. 2001;155(5):755-762.
27. Nagano O, and Saya H. Mechanism and biological significance of CD44 cleavage. Cancer Sci. 2004;95(12):930-935.

28. Gatenby RA, Gillies RJ. Why do cancers have high aerobic glycolysis? Nat Rev Cance. 2004; 4(11):891-899.

29. Tamada M, Suematsu M, Saya H. Pyruvate kinaseM2:Multiple faces for conferring benefits on cancer cells. Clin Cancer Res. 2012;18(20):5554 5561 .

30. Tamada M, Nagano O, Tateyama S, et al. Modulation of glucose metabolism by CD44 contributes to antioxidant status and drug resistance in cancer cells. Cancer Res. 2012;72(6):1438-1448.

31. Ros S, Santos CR, Moco S, et al. Functional metabolic screen identifies 6- phosphofructo-2-kinase/fructose-2, 6-biphosphatase 4 as an important regulator of prostate cancer cell survival. Cancer Discov. 2012;2(4):328-343.

32. Li W, Cohen A, Sun Y, et al. The Role of CD44 in Glucose Metabolism in Prostatic Small Cell Neuroendocrine Carcinoma. Molecular Cancer Research. 2016;14(4):344-353. 